\title{
Potentially Effective and Safe Anti-Helicobacter pylori Natural Products: Chemometric Study
}

\author{
BRANISLAVA D. KOCIĆ ${ }^{1}$, DOBRILA M. STANKOVIĆ ĐORĐEVIĆ ${ }^{2}$, \\ MARIJA V. DIMITRIJEVIĆ ${ }^{3}$, MARIJA S. MARKOVIĆ ${ }^{4}$, DRAGOLJUB L. MILADINOVIĆ ${ }^{*}$ \\ ${ }^{1}$ Institute for Public Health, Center for Microbiology, Blvd. Dr Zorana Đinđića 50, 18000 Niš, Serbia \\ ${ }^{2}$ University of Niš, Faculty of Medicine, Department of Microbiology and Immunology, Blvd. Dr Zorana Đinđica 81, \\ 18000 Nišs, Serbia \\ ${ }^{3}$ University of Niš, Faculty of Science and Mathematics, Department of Chemistry, Višegradska 33, 18000 Niš, Serbia \\ ${ }^{4}$ University of Niš, Faculty of Science and Mathematics, Department of Biology and Ecology, Višegradska 33, 18000 Niš, \\ Serbia \\ ${ }^{5}$ University of Niš, Faculty of Medicine, Department of Pharmacy, Blvd. Dr Zorana Đinđica 81, 18000 Niš, Serbia
}

\begin{abstract}
The susceptibility of Helicobacter pylori to three essential oils (EOs), 12 naturally occurring monoterpene hydrocarbons, oxygenated and phenolic monoterpenes and three reference antibiotics were studied. Classification and comparison of essential oils and monoterpenes on the basis of their chemical composition and antibacterial activity were made by the utilization of principal component analyses (PCA) and agglomerative hierarchical clustering (AHC). The most abundant compound in the Thymus glabrescens Willd. and Thymus pulegioides L. EOs is geraniol (33.8\% and 52.5\%), while the main constituent in Satureja kitaibelii Wierzb. ex Heuff. EO is limonene (16,1\%). The compound that was the most active against $H$. pylori was carvacrol. EOs of T. glabrescens and S. kitaibelii exhibit higher antibacterial ability in comparison with all monoterpenes, except carvacrol, probably based on the concept of synergistic activity of essential oil components. PCA separated essential oils based on chemical composition and explain $96.5 \%$ of the total variance in the first two principal components. Essential oils, phenolic monoterpenes and two antibiotics were classified in the same sub-cluster within AHC analyses. EOs of T. glabrescens and S. kitaibelii can be used to treat infections caused by $H$. pylori, as a potentially effective, cheap and safe natural products. Further research of antibacterial activity of selected monoterpenes, essential oils and standard antibiotic combinations, as well as clinical study are required.
\end{abstract}

Keywords: Chemometric, Helicobacter pylori, esential oils, monoterpenes, microdilution method

\section{Introduction}

Helicobacter pylori infection remains one of the common chronic bacterial infections affecting humans. Infection can be cured in a high percentage, however, the resistance of $H$. pylori to some antibiotics, limits the results of antibiotic therapy [1]. Therefore, it is necessary to develop alternative natural and safe methods for controlling infections of the human body. A variety of plant species is capable of synthesizing many substances which show antibacterial activity [2]. The antimicrobial effects of terpenes, the primary constituents of the essential oils, have been well known for centuries [3].

In the modern chemical and biological research, it is necessary to use chemometric methods in order to confirm experimental results and eliminate any kind of subjective interpretations and discussions. Principal component analyses is a statistical tool that transforms and reduces the dimensionality of numerical datasets into new uncorrelated variables. The advantage of this analysis is that it is an unsupervised method which means that PCA displays a visual representation of the dominant patterns in the data set. Agglomerative hierarchical clustering is a technique to classify a dataset of the system into clusters based on their similarities or dissimilarity. HCA creates a classification hierarchy starting from a division in which each object is a single cluster and ending with

*email: dragoljub.miladinovic@medfak.ni.ac.rs 
a division in which all the objects constitute a single cluster [4]. The main aim is to sort different variables into a cluster. When variables belong to the same cluster, they have a maximal degree of association and when they do not belong to the same cluster their degree of association is minimal.

In this study, we investigated the susceptibility of $H$. pylori NCTC 11638 to three essential oils isolated from Thymus pulegioides L., Satureja kitaibelii Wierzb. ex Heuff and Thymus glabrescens Willd. In our previous studies, these essential oils exhibited significant activity against a large number of bacteria [5-7]. To the authors' knowledge, the anti-Helicobacter pylori activity of selected essential oils has not been examined so far. Also, we tested 12 naturally occurring monoterpene hydrocarbons, oxygenated and phenolic monoterpenes as follows: $\gamma$-terpinene, limonene, geranyl acetate, borneol, camphor, menthol, eucalyptol, geraniol, linalool, eugenol, thymol and carvacrol. The antibacterial activities of reference antibiotics: metronidazole, tetracycline and clarithromycin were also determined.

\section{Materials and methods}

\subsection{Plant material and chemicals}

The aerial parts of T. pulegioides, S. kitaibelii and T. glabrescens were collected at the blooming stage in 2018. from natural populations at the Kravlje village, Serbia. Voucher specimens (accession numbers 13960, 13220 and 13221) are deposited at the Herbarium of the Department of Biology and Ecology, Faculty of Science and Mathematics, University of Niš (Herbarium Moesiacum Niš - HMN).

All chemicals, reagents and standards were of analytical reagent grade and were purchased from the Sigma-Aldrich Chemical Company (Germany) and Thermo Fisher Scientific (US).

\subsection{Oil isolation}

Aerial parts of the plant (dried and pulverized) were subjected to hydro-distillation for $4 \mathrm{~h}$, using Clevenger-type apparatus to produce oil. The resulting essential oils were dried over anhydrous sodium sulfate and stored at $4^{\circ} \mathrm{C}$.

\subsection{Gas chromatography}

The GC analysis of the oils was carried out on a GC HP5890 II apparatus, equipped with the splitsplitless injector, HP-5MS capillary column $(30 \mathrm{~m} \times 0.25 \mathrm{~mm}, 0.25 \mu \mathrm{m}$ film thickness $)$ with helium as the carrier gas $(1 \mathrm{~mL} / \mathrm{min})$ and flame ionization detector. Operating conditions were: injector temperature of $250^{\circ} \mathrm{C}$ and interface temperature of $280^{\circ} \mathrm{C}$; and temperature program from $50^{\circ} \mathrm{C}(3 \mathrm{~min})$ to $250^{\circ} \mathrm{C}$ at a rate of $3^{\circ} \mathrm{C} \mathrm{min}^{-1}$.

\subsection{Gas chromatography/mass spectrometry}

GC-MS analyses were performed on an Agilent Technologies apparatus, Model GS 6,890 N at 70 eV coupled with a mass selective detector MSD 5975C, under the same gas chromatograph conditions.

\subsection{Identification of compounds}

The identification of compounds was based on a comparison of Kovats retention indexes by the use of calibrated automated mass spectral deconvolution and identification system software AMDIS ver. 2.64 in combination with selective ion analysis (SIA) resolution method [8], compared with those from available literature [9], and by comparing their mass spectra to those from Wiley 275 and NIST/NBS libraries, using different search engines. Retention indexes were obtained by co-injection with an aliphatic hydrocarbons C9-C28 standard mixture.

\subsection{Antibacterial testing}

A broth microdilution method was used to determine the minimum inhibitory concentration (MIC) and minimum bactericidal concentration (MBC). Serial doubling dilutions of the tested essential oils and monoterpenes were prepared in dimethyl sulfoxide (DMSO) and then transferred in a 96/well 
microtiter plate over the range of 45-92160 $\mu \mathrm{g} / \mathrm{mL}$. For the experiment, Mueller-Hinton broth was used and supplemented with $10 \%$ horse serum. The final volume in each well of microtitre plates was $100 \mu \mathrm{L}$ and the final bacterial concentration was $108 \mathrm{CFU} \mathrm{mL}^{-1}$ in each well. The microtiter plates were incubated at $37^{\circ} \mathrm{C}$ under microaerobic conditions in a moist atmosphere for 3 days. In order to improve the broth method, the equal volumes $(100 \mu \mathrm{L})$ of double strengthened Christensen's urea broth were added into each well after incubation and plates were additionally incubated in an aerobic atmosphere at $37^{\circ} \mathrm{C}$.

The plates were examined visually for color change after $3 \mathrm{~h}$ Christensen's urea broth addition. To determine MBC, the broth was taken from each well without visible growth and inoculated in Columbia agar for 3 days at $37^{\circ} \mathrm{C}$.

\subsection{Statistical analysis of data}

Statistical analysis of data was performed using analysis of variance. To determine the statistical significance of the antibacterial activity, Student's t-test was used. A probability of p less than 0.05 was statistically significant. The essential oil components, monoterpenes, MIC and MBC values were subjected to principal components analysis and agglomerative hierarchical clustering using Statistica 8.0, StatSoft, Tulsa, Oklahoma, USA.

\section{Results and discussions}

The most abundant compound in the T. glabrescens and T. pulegioides EOs is geraniol (33.8\% and $52.5 \%$ ), while the main constituent in $S$. kitaibelii EO is limonene (16.1\%, Table 1). The main component of $S$. kitaibelii essential oil EO from many localities in southeastern Serbia is geraniol [5]. The sample from Kravlje village, after multiple checks, contains limonene, as the main component of essential oil. This fact will certainly be the subject of future research.

Table 1. Contents of the abundant compounds of selected essential oils ( $>3 \%)$

\begin{tabular}{|c|c|c|c|c|c|}
\hline Component & $\mathrm{AIE}$ & AIL & T. pulegioidus & S. kitaibelii & T. glabrescens \\
\hline a-Pinene & 929 & 932 & - & 5.8 & - \\
\hline p-Cymene & 1025 & 1022 & 3.4 & $13.4^{-}$ & 5.4 \\
\hline Limonene & 1030 & 1024 & - & 16.1 & - \\
\hline$\beta$-cis-ocimene & 1038 & 1032 & - & 7.6 & $=$ \\
\hline$\beta$-trans-ocimene & 1048 & 1044 & - & 5.5 & - \\
\hline$\gamma$-Terpinene & 1059.6 & 1054 & 4.3 & 10.5 & 3.1 \\
\hline Linalool & 1100.5 & 1095 & - & - & 5.5 \\
\hline Bomeol & 1173 & 1165 & - & 4.2 & - \\
\hline Geraniol & $1260^{-}$ & 1249 & 52.5 & - & 33.8 \\
\hline Carvacrol & $1289^{\circ}$ & 1293.1 & - & $8.0^{\circ}$ & - \\
\hline Thymol & 1294 & 1289 & $8.4^{-}$ & $3.4^{-}$ & 13.6 \\
\hline Geranyl acetate & 1384.9 & 1379 & $7.2^{-}$ & -- & 20.3 \\
\hline Caryophyllene & 1421.3 & $1417^{-}$ & 5 & - & - \\
\hline
\end{tabular}

The anti-H. pylori activities of selected essential oils, monoterpenes and reference antibiotics are presented in Table 2. Essential oils have been found to have antibacterial activity with a range of MIC values from 331.2 to $653.1 \mu \mathrm{g} / \mathrm{mL}$ and $\mathrm{MBC}$ values from 1324.8 to $1959.3 \mu \mathrm{g} / \mathrm{mL}$. The examined monoterpenes possessed antibacterial activities with MIC values ranging from 286.3 to $21250.4 \mu \mathrm{g}$ $/ \mathrm{mL}$, and MBC values from 286.3 to $85001.6 \mu \mathrm{g} / \mathrm{mL}$. The reference antibiotics metronidazole and tetracycline were active with the concentration of $512.8 \mu \mathrm{g} / \mathrm{mL}$, while $H$. pylori was resistant to clarithromycin. 
Table 2. Antibacterial activity of essential oils, selected monoterpenes and reference antibiotics $(\mu \mathrm{g} / \mathrm{mL})$

\begin{tabular}{|c|c|c|}
\hline Sample & MIC & $\mathrm{MBC}$ \\
\hline T. pulegidoides & $653.1^{\mathrm{h}}$ & $1959.3^{\mathrm{h}}$ \\
\hline S. kitaibelii & $393.8^{j}$ & $1575.2^{\mathrm{i}}$ \\
\hline T. glabrescens & $3312^{\mathrm{k}}$ & $1324.8 \mathrm{i}$ \\
\hline$\gamma$-terpinene & $212504^{a}$ & $85001.6^{a}$ \\
\hline limonene & $21025.7^{\mathrm{a}}$ & $84102.8^{\mathrm{a}}$ \\
\hline geranyl acetate & $11450.3^{\mathrm{b}}$ & $45801.2^{\mathrm{b}}$ \\
\hline bomeol & $4000.5^{c}$ & $16002^{\circ}$ \\
\hline menthol & $20009^{\mathrm{d}}$ & $8003.6^{\mathrm{d}}$ \\
\hline camphor & $2000.6^{\mathrm{d}}$ & $6001.8^{\circ}$ \\
\hline eucalyptol & $1441.5^{\circ}$ & $5766^{f}$ \\
\hline geraniol & $1389.1^{f}$ & $5556.4^{f}$ \\
\hline linalool & $1340.2^{f}$ & 4020.68 \\
\hline eugenol & $828.2 \mathrm{z}$ & $1656.4^{\mathrm{i}}$ \\
\hline thymol & $512.8^{i}$ & $512.8^{\mathrm{k}}$ \\
\hline carvacrol & $286.3^{\mathrm{k}}$ & $286.3^{1}$ \\
\hline metronidazole & $512.8^{i}$ & $512.8^{\mathrm{k}}$ \\
\hline tetracilcline & $512.8^{i}$ & $512.8^{\mathrm{k}}$ \\
\hline clarithromycin & - & - \\
\hline
\end{tabular}

A number of previous studies dealt with susceptibility of $H$. pylori to EOs, but they have used somewhat different methodologies/sets of bacteria, making comparison of the results difficult/ impossible. However, the antibacterial activity of carvacrol was higher than all examined samples, which is in agreement with the published data [10]. In our research the anti-H. pylori activity of essential oils of $T$. glabrescens and $S$. kitaibelii was higher than each of the monoterpenes, except carvacrol, which is in agreement with the literature data [11].

To demonstrate the possible connection between analyzed essential oils and monoterpenes, PCA method was applied. According to the eigenvalues of the obtained correlation matrix, the PC1 horizontal axis explained $73.3 \%$ of the total variance among the tested interactions, while the PC2 vertical axis showed a further $23.1 \%$ (Figure 1). Based on this, it could be concluded that the PC1 is better correlated with the variables than the PC2 which means it provides more information.

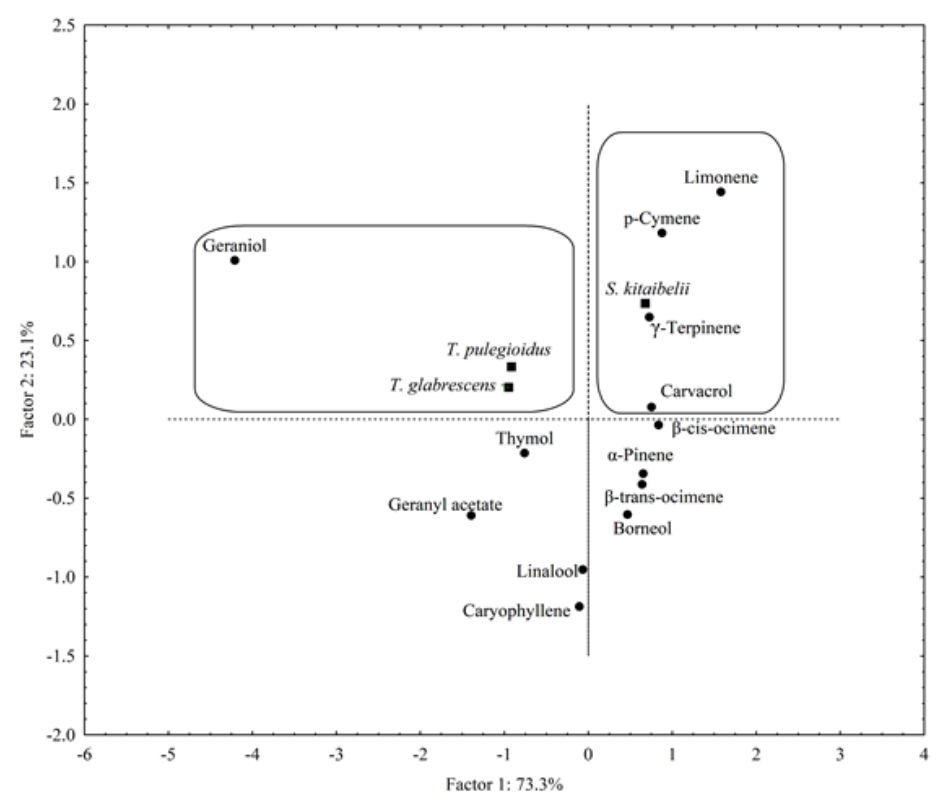

Figure 1. Principal component analysis carried out on data of chemical composition of essential oils in the loading plot 
It can see that $S$. kitaibelii essential oil is separate from $T$. glabrescens and $T$. pulegioides essential oils on the positive side of the plot, because only S. kitaibelii essential oil has positive loadings on PC1 (0.677), compared to the remaining two oils. It is expected because this oil has the highest concentrations of p-cymene, limonene, $\gamma$-terpinene and carvacrol which are located in this cluster. On the other side, linalool, thymol, geranyl acetate and caryophyllene are located diametrically opposite to S. kitaibelii essential oil. The location of these monoterpenes was expected because $S$. kitaibelii essential oil does not contain these components, except thymol which was presented in low concentrations. Location of $T$. glabrescens and $T$. pulegioides essential oils may be explained by the high content of geraniol which is the main compound in these essential oils.

The similarity of biologically active species was assessed using agglomerative hierarchical clustering and the results are shown as a dendrogram in Figure 2. The dendrogram was produced by the Single Linkage method as $D_{\text {link }} / D_{\max } \times 100=50$. The $A H C$ based on the Euclidean distance between groups indicated three clusters (A, B and C) of species which were identified by their MIC and $\mathrm{MBC}$ values. Monoterpene hydrocarbons $\gamma$-terpinene and limonene are associated in cluster A, with lowest antibacterial activity. Cluster B was constituted by the geranyl acetate; it stands out forming a separate cluster in $\mathrm{AHC}$ analyses. The third cluster $\mathrm{C}$ is divided into two sub-cluster. Borneol forms a separate sub-cluster $\left(C_{1}\right)$, while the second sub-cluster $C_{2}$ is divided into two subcluster, $\mathrm{C}_{2}{ }^{\prime}$ and $\mathrm{C}_{2}{ }^{\prime \prime}$. Researched essential oils with eugenol, thymol, carvacrol and reference antibiotics are associated in a separate sub-cluster $\mathrm{C}_{2}{ }^{\prime \prime}$ because of exhibit the highest antibacterial activity against H. pillory. The rest of monoterpenes is classified in sub-cluster $\mathrm{C}_{2}{ }^{\prime}$.

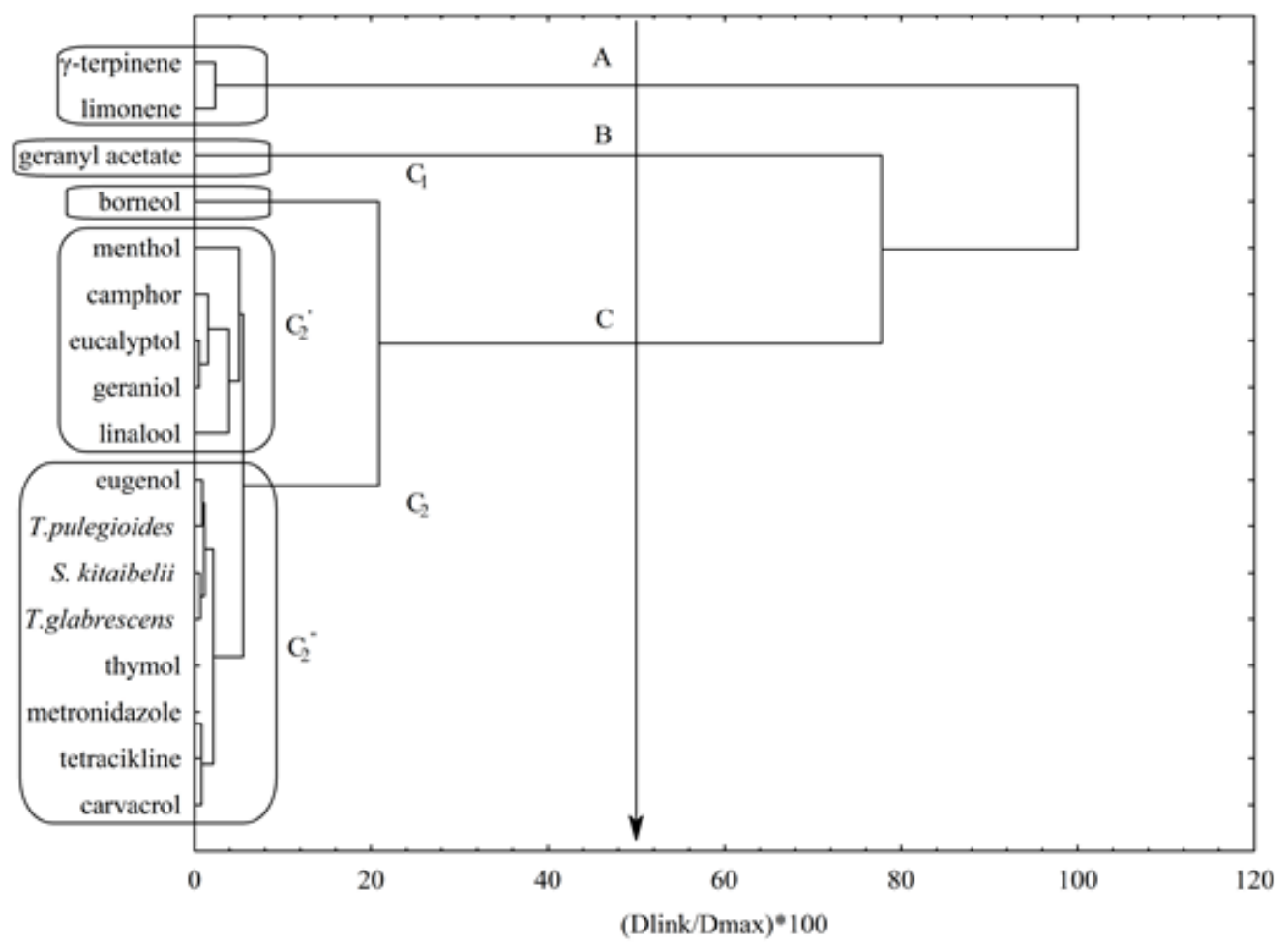

Figure 2. Dendrogram showing clustering of selected monoterpenes, essential oils and reference antibiotics based on their MIC and MBC values

Difficulties associated with such studies, as we said, are that the test method used for the assessment of antimicrobial activity is often the disc diffusion method. This method is highly dependent on water solubility and the ability of test components to diffuse through an agar and inhibits the growth of the test microorganism. Thus, it would be expected that compounds of lower water solubility would show less activity, even if solubility did not affect their activity in other situations [12]. However, since the bacterial growth inhibition does not mean bacterial death, this method cannot 
distinguish bactericidal and bacteriostatic effects. Moreover, the agar disk-diffusion method is not appropriate to determine the minimum inhibitory concentration, as it is impossible to quantify the amount of the antimicrobial agent diffused into the agar medium [13]. These facts determined microwell dilution assay as a method of choice.

We found that the anti-Helicobacter pylori effect of carvacrol was higher, compared with all examined antibacterial substances. The hydroxyl group of carvacrol has potency as transmembrane carrier for monovalent cations, also destroys enzymes and other essential macromolecules [14]. The antibacterial activities of essential oils are due to their ability to permeabilize the membranes by disrupting the lipid structure, dissipation of the proton motive force, and impairment of intracellular $p \mathrm{H}$ homeostasis [15]. Based on PCA analysis, it could be hypothesized that the antibacterial activity of T. glabrescens and T. pulegioides essential oils is connected with the significant percentage of geraniol, which is the main component of these oils. In AHC analysis T. glabrescens and S. kitaibelii EOs are clustered with phenolic compounds (thymol, eugenol and carvacrol). Despite the small amount of thymol and carvacrol in discussed EOs, they could influence the antibacterial activity of the essential oil to a significant extent. Furthermore, it is reported that some terpenes in the presence of some antimicrobial agent showed a synergistic effect, for example, the presence of p-cymene along with carvacrol may enhance its antimicrobial activity of essential oil [14]. There are limited data dealing with the mechanism of action of combinations of the essential oil components. However, there are some studied mechanisms of antimicrobial interaction that produce synergism. They include the partial inhibition of a common biochemical pathway, inhibition of protective enzymes and use of cell wall active agents to enhance the uptake of other antimicrobials [16]. These facts can be applied to all the essential oils we have studied. It can be assumed that the minor components of the essential oils can have a significant impact on the antibacterial activity of the dominant components, and therefore on the essential oil.

\section{Conclusions}

This is the first report on EOs activity of selected plants against $H$. pylori. Also, anti-Helicobacter pylori activity of borneol has not been examined yet. The most abundant compound in the $T$. glabrescens and T. pulegioides EOs is geraniol (33.8 and 52.5\%), while the main constituent in $S$. kitaibelii EO is limonene $(16.1 \%)$. The compound that was the most active against $H$. pylori was carvacrol. EOs of T. glabrescens and S. kitaibelii exhibit higher antibacterial ability in comparison with all monoterpenes, except carvacrol, probably based on the concept of synergistic activity of essential oil components. PCA separated essential oils based on chemical composition and explain 96.5\% of the total variance in the first two principal components. EOs, phenolic monoterpenes and two antibiotics were classified in the same sub-cluster within AHC analyses. T. glabrescens and $S$. kitaibelii EOs can be used to treat infections caused by Helicobacter pylori, as a potentially effective, cheap and safe natural products. Further research of antibacterial activity of selected monoterpenes, essential oils and standard antibiotic combinations, as well as clinical study are required.

Acknowledgments: This research was supported by the Ministry of Education, Science and Technological Development of the Republic of Serbia.

\section{References}

1.EL-DIN, M.I.G., YOUSSEF, F.S., ASHOUR, M.L., ELDAHSHAN, O.A., SINGAB, A.N.B., Comparative Analysis of Volatile Constituents of Pachira aquatica ubl. And Pachira glabra Pasq., their Anti-Mycobacterial and Anti-Helicobacter pylori Activities and their Metabolic Discrimination using Chemometrics. J. Essent. Oil Bearing Plants. 21(6), 2018, 1550-1567.

2.JOSHI, D., NAILWAL, M., MOHAN L., MELKANI, A.B., Ligularia amplexicaulis (wall.) DC. Essential oil composition and antibacterial activity. J. Essent. Oil Bearing Plants. 30(3), 2018, 189-196. 
3.OHNO, T., KITA, M., YAMAOKA, Y., IMAMURA, S., YAMAMOTO, T., MITSUFUJI, S., KODAMA, T., KASHIMA, K., IMANISHI, J., Antimicrobial activity of essential oils against Helicobacter pylori. Helicobacter. 8(3), 2003, 207-215.

4.EFENBERGER-SZMECHTYK, M., NOWAK A., KREGIEL D., Implementation of chemometrics in quality evaluation of food and beverages. Crit. Rev. Food Sci. Nutr. 58(10), 2017, 1747-1766.

5. MILADINOVIC, D., ILIC, B., KOCIC, B., MILADINOVIC, M., An in vitro antibacterial study of savory essential oil and geraniol in combination with standard antimicrobials. Nat. Prod. Commun. 9(11), 2014, 1629-1632.

6.MILADINOVIC, D., ILIC, B., KOCIC, B., CIRIC, V., NIKOLIC, D., Antibacterial investigation of thyme essential oil and its main constituents in combination with tetracycline. J. Med. Food. 18(8), 2015, 935-937.

7.MILADINOVIC, D., ILIC, B., MILADINOVIC, LJ., KOCIC, B., CIRIC, V., STANKOV-JOVANOVIĆ, V. CVETKOVIĆ, O., Antibacterial activity of Thymus pulegioides essential oil and its synergistic potential with antibiotics: a chemometric approach, in: Govil, J.N., Bhattacharya, S. (Eds) Recent Progress in Medicinal Plants vol. 38: Essential Oils III and Phytopharmacology. Houston: Studium Press LLC; pp. 2013, 101-136.

8.TAN, B., LIANG, Y., YI, L., LI, H., ZHOU, Z., JI, X., DENG J. Identification of free fatty acids profiling of type 2 diabetes mellitus and exploring possible biomarkers by GC-MS coupled with chemometrics. Metabolomics. 6, 2010, 219-228.

9.ADAMS, R.P., Identification of essential oil components by gas chromatography/mass spectroscopy. Allured Publishing Co. Carol Stream, Illinois, 2007.

10.BALOUIRI, M., SADIKI, M., IBNSOUDA, S.K., Methods for in vitro evaluating antimicrobial activity: A review. J. Pharm. Anal. 6(2), 2016, 71-79.

11.EFTEKHARA, F., NARIMAN, F., YOUSEFZADI, M., HADIAN, J., NEJA, S., Anti-Helicobacter pylori activity and Essential Oil Composition of Thymus caramanicus from Iran. Nat. Prod. Commun. 4(8), 2009, 1139-1142.

12.MILADINOVIC, D.L., ILIC, B.S., MIHAJILOV-KRSTEV, T.M., NIKOLIC, N.D., MILADINOVIC, L.C., CVETKOVIC, O.G., Investigation of the chemical composition antibacterial activity relationship of essential oils by chemometric methods. Anal. Bioanal. Chem. 403, 2012, 1007-1018.

13.ULTEE, A., BENNIK, M.H., MOEZELAAR, R., The phenolic hydroxyl group of carvacrol is essential for action against the food-borne pathogen Bacillus cereus. Appl. Environ. Microbiol. 68(4), 2002, 15611568.

14.FALSAFIA, T., MORADI, P., MAHBOUBI, M., RAHIMI, E., MOMTAZ, H., HAMEDI, B., Chemical composition and anti-Helicobacter pylori effect of Satureja bachtiarica Bunge essential oil. Phytomed. 22(1), 2015, 173-177.

15.BERGONZELLI, G.E., DONNICOLA, D., PORTA, N., CORTHÉSY-THEULAZ, I.E., Essential Oils as Components of a Diet-Based Approach to Management of Helicobacter Infection. Antimicrob. Agents Chemother. 47(10), 2003, 3240-3246.

16.BASSOLÉ, I.H.N., JULIANI, H.R., Essential Oils in Combination and Their Antimicrobial Properties. Molecules. 17(4), 2012, 3989-4006.

Manuscript received: 29.02 .2020 